\title{
Investigating anti-neuroinflammatory mechanism of orientin in lipopolysaccharide-induced BV2 microglia cells
}

\author{
Pei Hong Ganª Erna Laere ${ }^{\mathrm{a}}$, Anna Pick Kiong Ling ${ }^{\mathrm{a}^{*}}$, Kenny Gah Leong Voon ${ }^{\mathrm{b}}$, Rhun Yian Koh ${ }^{\mathrm{a}}$, \\ Ying Pei Wong ${ }^{a}$ \\ "Division of Applied Biomedical Sciences and Biotechnology, School of Health Sciences, International Medical University, Bukit Jalil 57000 \\ Kuala Lumpur, Malaysia \\ ${ }^{b}$ Department of Pathology, School of Medicine, International Medical University, Bukit Jalil, 57000 Kuala Lumpur, Malaysia
}

Received 15th February 2019 / Accepted 31st March 2019

\begin{abstract}
Chronic neuroinflammation in central nervous system (CNS) can lead to neurodegenerative diseases (ND). This was due to the over-activated microglia, which releases excessive pro-inflammatory mediators. The molecular mechanisms of orientin as anti-neuroinflammatory are yet to be fully elucidated. In order to investigate the effect of orientin on LPS-stimulated BV2 microglial cells, the cells were pretreated with orientin at maximum non-toxic dose (MNTD) $(15 \mu \mathrm{M})$ or half MNTD $(1 / 2 \mathrm{MNTD})(7.5 \mu \mathrm{M})$ for 3 hours, followed by incubation with $0.1 \mu \mathrm{g} / \mathrm{mL}$ of LPS for 24 hours. The LPS-stimulated cells were then subjected to three series of studies, including the determination of ROS level using 2',7'dichlorofluorescindiacetate (DCFH-DA) methods and the determination of mRNA of nuclear factor (NF) - $\mathrm{kB}$, Signal transducer and activator of transcription 1 (STAT1), inducible nitric oxide synthase (iNOS), cyclooxygenase-2 (COX-2)and heme oxygenase-1 (HO-1) via real-time PCR (qPCR). The findings from this study demonstrated the probable mechanism of orientin in treating neuroinflammation via the downregulation of ROS level, STAT1, NF-кB, iNOS and COX-2 whilst upregulating HO-1. Validation of molecular mechanism of orientin suggested that it could be a potential therapeutic agent in treating ND.
\end{abstract}

Keywords: anti-neuroinflammatory, microglia, neurodegenerative diseases, neuroinflammation, orientin

\section{INTRODUCTION}

Neurodegenerative diseases (ND), such as Alzheimer's disease (AD), Parkinson's diseases (PD), Huntington disease, amyotrophic lateral sclerosis (ALS), multiple sclerosis, etc. are diseases characterized by progressive damage in the nerve cells. The deterioration will gradually result in the loss of motor and also cognitive functions such as memory and decision making (Chen et al., 2016). According to National Institute of Health (NIH), ND affect millions of people worldwide, with $\mathrm{AD}$ and $\mathrm{PD}$ as the most common types (Katzman, 2008). It was reported that there are more than 5 million American living with AD, while roughly 500,000 living with PD (Katzman, 2008). The cases were expected to increase from 13.5 million in 2000 to 36.7 million in 2050 (Katzman, 2008). Even though the etiologies of ND remain unclear, recent studies indicated that neuroinflammatory processes are closely related to several neurodegenerative pathways leading to ND (Chen et al., 2016; FrankCannon et al., 2009, Streit et al., 2004).

\footnotetext{
* Author for correspondence: Dr. Anna Pick Kiong Ling, Division of Applied Biomedical Sciences and Biotechnology, School of Health Sciences, International Medical University, Bukit Jalil 57000 Kuala Lumpur, Malaysia.
} Email - anna_ling@imu.edu.my 
Microglia cells are said to be the key cellular mediators of neuroinflammatory processes, which result in ND (Frank-Cannon et al., 2009, Streit et al., 2004; Rojo et al., 2008; Rogers et al., 2007). Studies suggested that when there are stimulus such as lipopolysaccharide (LPS), hypoxia, trauma or neurotoxins acting on microglia cells, it will initiate the neuroinflammatory response in central nervous system (CNS) by releasing pro-inflammatory cytokines, such as tumour necrosis factor-á (TNF- $\alpha$ ), interleukin-1 $\alpha$ (IL- $1 \alpha$ ), and IL-6 (Chen et al., 2016, Frank-Cannon et al., 2009; Nakajima $\&$ Kohsaka, 2001). The release of these proinflammatory cytokines will eventually lead to the activation of transcription factors, such as nuclear factor kappa-B (NF-кB) and signal transducer and activator of transcription 1 (STAT1) (Lawrence, 2009), with subsequent upregulation of inducible nitric oxide synthase (iNOS) and cyclooxygenase-2 (COX-2) in order to get rid of the intruders and tissue damage, hence promoting the neuronal survival (Chen et al., 2016; Frank-Cannon et al., 2009; Nakajima \& Kohsaka, 2001; Hsieh \& Yang, 2013). In short, the transmembrane receptor in CNS will firstly recognize the inflammatory stimulus followed by the transmission of the signal to the nucleus for pro-inflammatory gene activations(Ahmed et al., 2015). This activation of pro-inflammatory genes is then controlled by the selective binding of transcription factors to the promoters of these genes (Ahmed et al., 2015).

However, when the cells are left untreated, it will eventually result in sustained activation of the microglia cells, causing uncontrolled release of pro-inflammatory factors that lead to continuous activation of $\mathrm{NF}-\mathrm{KB}$ and STAT1, which then result in high expression of iNOS and COX-2 and eventually contribute to chronic neuroinflammation. In addition, over-activated microglia cells may also produce excessive amounts of reactive oxygen species (ROS) leading to oxidative stress (Hsieh \& Yang, 2013; Yune et al., 2004; Massa et al., 2006). As a normal feedback mechanism, this oxidative stress will trigger the upregulation of heme oxygenase-1 (HO-1), regulating the imbalance ROS levels, hence, exerting an anti-oxidative and antineuroinflammatory effects (Hiseh et al., 2013; Chau, 2015). In short, the uncontrolled release of pro-inflammatory factors and the oxidative stress will lead to chronic neuroinflammation, causing cumulative neuronal dysfunction, neuronal death and eventually neurodegenerative disorders (Luu \& Block, 2010). Therefore, targeting the microglia cells could be one of the potential therapeutic approaches in treating ND.

The current anti-inflammatory agents are nonsteroidal agents (NSAIDs), such as indomethacin and rofecoxib, which are shown to have anti-neuroinflammatory effects (Kulkarni et al., 2005; Ajmone-Cat et al., 2010). However, these drugs were known to cause adverse effects in long term treatment (Kulkarni et al., 2005). For instance, Kanatani et al. suggested that indomethacin is associated with the damage of gastric mucosal (Kanatani et al., 2004). Besides, rofecoxib was shown to possess cardiotoxicity that will lead to heart failure (Mamdani et al., 2004). Due to all these adverse effects of NSAIDs, researchers started to divert their focus on some active constituents derived from medicinal plants, particularly the flavonoids. For example, studies have shown that flavonoid quercitrin extracted from Juglans mandshurica could be a potent anti-neuroinflammatory agent (Kulkarni et al., 2005). Besides, flavonoid such as cudraflavanone D and paeonol have shown their anti-neuroinflammatory responses in activated microglia cells through the inhibition of nitric oxide (NO), ROS production and the expression of NF-кB, iNOS and COX-2 (Lin et al., 2015; Himaya et al., 2012; Kim et al., 2016), whereas curcumin was found to induce the HO-1 expression in microglia cells, providing an antioxidative effects (Parada et al., 2015). In addition, both oroxylin A and luteolin have also shown to suppress the expression of $\mathrm{NF}-\kappa \mathrm{B}$ and STAT1 in LPS-induced BV2 microglia cells, which resulted in its anti-neuroinflammatory effects (Liu et al., 2012; Kao et al., 2011).

In this study, orientin was chosen among all the flavonoids. Orientin is a water-soluble $c$ glycoside flavonoids that can be found or isolated from various medicinal plants such as Ocimum sanctum (holy basil), Phyllostachys species (bamboo leaves), Passiflora species (passion flowers), Trollius species (Golden Queen), and Jatrophagossypifolia (Bellyache Bush) (Lam et al., 2016). Orientin are widely reported to have beneficial properties such as anti-oxidative (An et al., 2012), anti-thrombotic 
and anti-platelet (Lee \& Bae, 2015), anti-viral and anti-bacterial (Li et al., 2004), anti-inflammation (Bae, 2015), vasodilation (Fu et al., 2005), neuroprotective (Law et al., 2014), radioprotective (Nayak et al., 2006), anti-adipogenesis (Kim et al., 2010) and antinociceptive (Da Silva et al., 2010), anti-inflammatory and anti-oxidative properties (An et al., 2012; Bae, 2015; Kim et al., 2010; Yu et al., 2015; Seo et al., 2012) that has stimulated the interest to further study this compound in the present study. At the molecular level, Yu et al. showed that orientin could alleviates oxidative stress in $\beta$-amyloid $(A \beta)$-mediated mouse model with Alzheimer's disease through the activation of Nrf2/HO-1 signaling (Seo et al., 2012). The activation of this signaling pathway induced the translocation of $\mathrm{Nrf} 2$, which then upregulated the expression of HO-1, activating the redox signaling pathway by exerting an anti-oxidative property (Seo et al., 2012). In addition, Seo et al. suggested that orientin isolated from Spirodela polyrbiza ethanolic extract possesses antiinflammatory effect through the inhibition of iNOS and COX-2 expression by attenuating the expression of NF-кB p65 in LPS-induced RAW264.7 cells (Kim et al., 2010; Matsuo et al., 2005).

Even though orientin has demonstrated various bioactivities, its anti-neuroinflammatory activity is not well studied or elucidated. Thus, this is a worthwhile study as elucidation of molecular mechanism could contribute largely in the development of new therapeutics that are capable of preventing neuroinflammation. As a potential therapeutic agent in treating $\mathrm{ND}$, the bioavailability of orientin in crossing the bloodbrain barrier (BBB) is a concern. There has been study suggesting that orientin have difficulty in crossing the BBB ( $\mathrm{Li}$ et al., 2008). However, studies showed that the function of $\mathrm{BBB}$ is altered in ND (Ohtsuki et al., 2010; Jaeger et al., 2009). Therefore, although orientin have difficulty in crossing $\mathrm{BBB}$ under normal physiological condition, the $\mathrm{BBB}$ permeability of compound might be altered and enhanced in neurodegenerative conditions. Hence, with the objectives to determine the effects of intracellular reactive oxygen species (ROS) and the mRNA and protein expression of iNOS, COX-2, STAT1, NF-кB and HO-1 upon treatment with orientin, these findings could reveal the possibility of orientin to be used as potential therapeutic agent in neuronal diseases.

\section{MATERIALS AND METHOD}

\section{Preparation of orientin stock solution. The} pure orientin compound was purchased from Sigma Aldrich, USA. It was then dissolved in dimethyl sulfoxide (DMSO) (Sigma Aldrich, USA) to prepare a $22.3 \mathrm{mM}$ of stock solution. Then, the stock solution was further diluted to the desirable concentrations using complete Dulbecco's Modified Eagle Medium (DMEM) medium (GIBCO, USA) before treating the cells.

Cell culture and maintenance. The BV2 microglia cells used in this study was provided by Dr. Sharmili of University Putra Malaysia (UPM). BV2 cells are a primary form of active immune defense in the central nervous system and had been reported to be a valid model and substitute for primary microglial in many experimental settings (Henn et al., 2009; Ackerman et al., 2015). The cells were cultured in complete DMEM medium supplemented with 10\% fetal bovine serum (FBS) (GIBCO, South America), 1\% Penicillin and Streptomycin (GIBCO, South America), 0.1\% Fungizone (GIBCO, South America) and $0.1 \%$ gentamycin (GIBCO, China), and were maintained in a $5 \% \mathrm{CO}_{2}$ incubator (RS Biotech, UK) at $37^{\circ} \mathrm{C}$.

For continuous maintenance, the cells were subcultured into new tissue culture flasks (Corning, USA) when the confluency reached $70 \%$. The procedures were initiated with the removal of culture medium, followed by washing with $2 \mathrm{~mL}$ of sterile phosphate buffer solution (PBS) (AMRESCO, USA). Next, $1 \mathrm{~mL}$ of $0.25 \%$ trypsin-EDTA (GIBCO, Canada) was added and incubated for few minutes in the $5 \% \quad \mathrm{CO}_{2}$ incubator at $37^{\circ} \mathrm{C}$. As soon as the cells detached, $1 \mathrm{~mL}$ of fresh culture medium was added into the flask in order to inactivate the trypsin. Then, the cell suspension was centrifuged at $0.4 \mathrm{~g}$ for $5 \mathrm{~min}$. After centrifugation, the supernatant was then discarded and the pellet was resuspended with 2 $\mathrm{mL}$ culture medium. Lastly, $1 \mathrm{~mL}$ of the cell 
suspension was added into each new T-flask containing $4 \mathrm{~mL}$ fresh culture medium.

As for storage purpose, the pellet was resuspended with $1 \mathrm{~mL}$ of freezing medium consisting of $10 \%$ DMSO and $90 \%$ FBS after the centrifugation step. It was then transferred to cryovial and stored at $-80^{\circ} \mathrm{C}$ or liquid nitrogen.

\section{Determination of maximum non-toxic dose} (MNTD). About $100 \mu \mathrm{L}$ of BV2 microglial cells at the density of $8 \times 10^{4}$ cells per $\mathrm{mL}$ were seeded in 96-well plates (Corning, USA). Once the confluency of the cells reached about $70 \%$, the medium was removed from each well and the cells were treated with a range of orientin concentrations $(0,0.032,0.16,0.80,4,20$ and 100 $\mu \mathrm{M})$ to determine its cytotoxic effect on BV2 microglial cells. After 24 hours of incubation, the viability of the cells was assessed using MTT assay by adding $20 \mu \mathrm{L}$ of $5 \mathrm{mg} / \mathrm{L}$ MTT (Bio Basic, Canada) into the wells containing BV2 microglial cells. After 4 hours of incubation at $37^{\circ} \mathrm{C}$, the solution was removed carefully. Then, $100 \mu \mathrm{L}$ of solvent grade DMSO (Friendemann Schmidt, Germany) was added and mixed well to dissolve the formazan. The absorbance was then measured at $570 \mathrm{~nm}$ using microplate reader (Dynex, USA). Based on the absorbance measured, the percentage of cells viability as well as percentage of cytotoxicity were calculated using the following formulae:

Percentage of viability (\%)

Absorbance reading of treated cells - Absorbance reading of medium

Absorbance reading of control cells - Absorbance reading of medium $X 100 \%$

Percentage of cytotoxicity $(\%)=100 \%$ - percentage of cell viability $(\%)$

\section{Determination of optimal lipopolysaccharide} (LPS) concentration. A total of $1 \times 10^{5}$ BV2 microglial cells were seeded in each well of 24 -well plate (Nuclon, Denmark). At 70\% confluent, the cells were treated with $0.0,0.1,1.0$ or $10.0 \mu \mathrm{g} / \mathrm{mL}$ of LPS (Sigma, USA) and incubated for 24 hours. After 24 hours, the level of nitric oxide (NO) being released was measured. Griess test was used to measure the nitric oxide level, whereby $50 \mu \mathrm{L}$ of the supernatant was mixed with $50 \mu \mathrm{L}$ Griess reagent (Sigma, Germany). After 15 minutes, the absorbance reading at $540 \mathrm{~nm}$ was measured using microplate reader (Molecular Devices, USA). In this study, fresh culture medium was used as the control. The effects of LPS on the morphology of the cells were observed under inverted microscope (Nikon Eclipse Ti-80, Japan) at 100x magnification and compared with the untreated cells.

Cell treatment and stimulation. BV2 microglia cells at density of $5 \times 10^{5}$ cells per well was seeded in $60 \mathrm{~mm}$ petri dishes (Thermo Scientific, USA) and incubated for 24 hours. Once the confluency of the cells reach about 70 to $80 \%$, the cells were treated with orientin at MNTD $(15 \mu \mathrm{M}$ as determined above) or half MNTD $(7.5 \mu \mathrm{M})$ and were incubated for 3 hours. Next, $0.1 \mu \mathrm{g} / \mathrm{mL}$ of lipopolysaccharide (LPS) (Sigma Aldrich, USA) was added to the treated cells to stimulate inflammation and was further incubated for 24 hours. After 24 hours, the cells were subjected to determination of intracellular ROS level, the mRNA expression of iNOS, COX-2, STAT1, NF-кB and HO-1 through real time PCR. An independent set was conducted for the determination of ROS as well as mRNA expression, respectively. In this study, indomethacin (Sigma Aldrich, USA) at $25 \mu \mathrm{M}$ was used as the positive control. All the studies were conducted with 7 treatment groups: (1) untreated cells, (2) cells treated with $1 / 2$ MNTD $(7.5 \mu \mathrm{M})$, (3) cells treated with MNTD $(15 \mu \mathrm{M})$, (4) cells treated with $0.1 \mu \mathrm{g} / \mathrm{mL}$ LPS, (5) cells treated with $1 / 2 \operatorname{MNTD}(7.5 \mu \mathrm{M})$ and $0.1 \mu \mathrm{g} / \mathrm{mL}$ LPS, (6) cells treated with $1 / 2$ MNTD $(7.5 \mu \mathrm{M})$ and $0.1 \mu \mathrm{g} / \mathrm{mL}$ LPS, (7) cells treated with $25 \mu \mathrm{M}$ Indomethacin and $0.1 \mu \mathrm{g} / \mathrm{mL}$ LPS, (8) cells only.

\section{Determination of reactive oxygen species (ROS) level. After 24 hours of incubation with} LPS, the medium and cells were collected and centrifuged at $0.4 \mathrm{~g}$ for $5 \mathrm{~min}$. After centrifugation, the pellet was resuspended in PBS. Next, $100 \mu \mathrm{L}$ of each cell suspension was added into 96-well plates (Corning, USA), which then followed by the addition of $100 \mu \mathrm{L}$ of $40 \mu \mathrm{M} \quad 2^{\prime}, 7^{\prime}$ dichlorofluorescindiacetate (DCFH-DA) (Sigma Aldrich, USA). The contents were mixed well and were measured at excitation wavelength of 485 $\mathrm{nm}$ and emission wavelength of $538 \mathrm{~nm}$ using Tecan Infinite F200 Multifunctional Microplate Reader (Tecan, USA) after 10 min of incubation.

Then, the cell concentration was determined using trypan blue exclusion methods, in which 10 
$\mu \mathrm{L}$ of the sample was mixed with $10 \mu \mathrm{L}$ of trypan blue (Thermo Scientific, USA). A total of $10 \mu \mathrm{L}$ of the suspension was then placed on the haemocytometer (Abcam, USA) for cell counting and the cell concentration of each treatment was calculated. The ROS level in each treatment was expressed as Relative Fluorescence Unit (RFU) per unit of cells.

Determination of $\boldsymbol{m} \boldsymbol{R} \boldsymbol{N} \boldsymbol{A}$ expression. After 24 hours of incubation with LPS, RNAs were extracted and purified from the treated and untreated BV2 microglia cell lines by PureLink $\AA$ RNA Mini Kit (Ambion, USA). Then, cDNA was synthesized from the RNA in Peltier Thermal Cycler-100 (MJ Research, USA) through qPCRBIO cDNA Synthesis Kit (PCR Biosystems, UK) following the manufacturer's instructions. Measurement of cDNA was then carried out using Tecan Infinite F200 Multifunctional Microplate Reader at Nanoquant filter wavelength of $260 \mathrm{~nm}$. Then, equal amount of cDNA samples $(50 \mu \mathrm{g})$ with $2 \mathrm{X}$ qPCRBIOSyGreen and specific iNOS, COX-2, STAT1, NF-кB (subunit p65), $\mathrm{HO}-1$ and $\beta$-actin forward and reverse primers (Table 1) were added and mixed well in semiskirted 96-well PCR plates (Molecular Bioproducts, USA). Quantitative real-time PCR was performed using iQ5 Multicolor Real-Time PCR Detection System (Bio-Rad, US). Lastly, the mRNA expression level of iNOS, COX-2, STAT1, NF-кB, HO-1 and $\beta$-actin were analysed and $\mathrm{CT}$ values were obtained. In this study, $\beta$ actin was used as the housekeeping gene in normalization of data. Relative mRNA expression were determined using Double Delta CT analysis (Kenneth \& Thomas, 2002).

Table 1. Forward and reverse primers sequences of genes analyzed in real time PCR.

\begin{tabular}{cll}
\hline Gene & \multicolumn{1}{c}{ Forward } & \multicolumn{1}{c}{ Reverse } \\
\hline iNOS & 5'-CCTCCTCCACCCTACCAAGT-3' & 5'-CACCCAAAGTGCTTCAGTCA-3' \\
COX-2 & 5'-TGGGTGTGAAGGGAAATAAGGA-3' & 5'-GAAGTGCTGGGCAAAGAATG-3' \\
STAT1 & 5'-CTGAATATTTCCCTCCTGGG-3' & 5'-TCCCGTACAGATGTCCATGAT-3' \\
NF-kB & 5'-CTGGTGGACACATACAGGAAGAC-3' & 5'-ATAGGCACTGTCTTCTTTCACCTC-3' \\
HO-1 & 5'-AGCCCCACCAAGTTCAAACA-3' & 5'-CATCACCTGCAGCTCCTCAA-3' \\
3-actin & 5'-TCCTCCTGAGCGCAAGTACTCT-3' & 5'-GCTCAGTAACAGTCCGCCTA-3' \\
\hline
\end{tabular}

The abbreviations of genes; iNOS: inducible nitric oxide synthase; COX-2: cyclooxygenase-2; STAT1: signal transducer and activator of transcription 1; NF-кB: nuclear factor kappa-light-chain-enhancer of activated B cells; HO-1: heme oxygenase-1; $\beta$-actin: Beta-actin.

Statistical analysis. The data obtained from three independent experiments with triplicates each were analysed and represented as mean \pm $\mathrm{SD}$ (standard deviation). Significant differences at $p<0.05$ were examined using One way analysis of variance followed by Tukey's multiple comparison test using SPSS 11.0 software (SPSS, Inc., Chicago, IL, USA).

\section{RESULTS AND DISCUSSION}

Determination of MNTD. MNTD is the highest concentration of orientin that did not cause any cytotoxic effect on BV2 microglia cells. It was determined by plotting a graph of percentage of cytotoxicity against concentrations of orientin (Figure 1). From Figure 1, there was a very clear relationship between the orientin concentrations and its cytotoxic effect on the cells. The studies demonstrated that at $\leq 15 \mu \mathrm{M}$ of orientin, the concentrations were not cytotoxic to BV2 microglia cells. Thus, the MNTD and $1 / 2$ MNTD of orientin that were determined in this study were $15 \mu \mathrm{M}$ and $7.5 \mu \mathrm{M}$, respectively. At these concentrations, BV2 cells showed a normal morphology of small soma with distal arborization, characteristic of "ramified" microglia (Dai et al., 2015). This concentration is lower than the MNTD of orientin $(20 \mu \mathrm{M})$ towards SH-SY5Y cells (Law et al., 2014). By comparing MNTD of orientin in these two cells, it seems to indicate that orientin is more toxic towards BV2 microglia cells compared to $\mathrm{SH}$ SY5Y cells. Based on this comparison, it proved 
that the cytotoxic effect of orientin might depended on the treated cell types, most probably due to structure-cytotoxicity relationship between orientin and the cells (Matsuo et al., 2005). It was proposed that cytotoxic effect of flavonoids will be higher if the permeability of the cells towards them is higher (Matsuo et al., 2005).

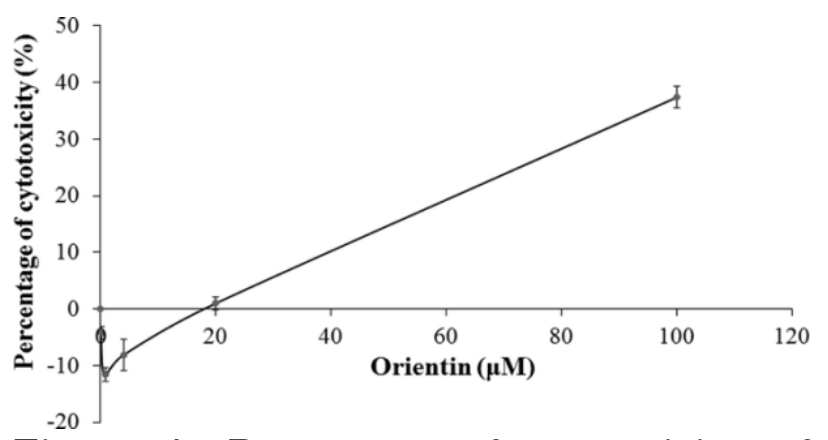

Figure 1. Percentage of cytotoxicity of orientin on BV2 microglial cells. After 24 hours of incubation with orientin at the range of 0 to $100 \mu \mathrm{M}$, the viability of the cells was measured by MTT assay. At $\leq 15 \mu \mathrm{M}$ of orientin, the concentrations were not cytotoxic to BV2 microglia cells. MTT, 3-[4,5-dimethylthiazol-2yl]-2,5-diphenyltetrazolium bromide.

Meanwhile, at lower concentration, particularly at $0.16 \mu \mathrm{M}$, negative cytotoxicity values were recorded that indicated that orientin exhibited promoting growth effects on BV2 microglia cells. At this concentration, the growth of BV2 cells was promoted by $4.19 \%$ as compared to the untreated cells. This observation might be due to the antioxidant activity of orientin that helped to scavenge the excessive free radicals produced in normal cells during ATP production in mitochondria, which eventually promote the growth of the cells (Praveena et al., 2014, Middleton et al., 2000; Khan, 2012; Spencer et al., 2012; Droge, 2002). The high antioxidant activity of orientin are known to be due to the presence of ring B, C-glucoside, maximum numbers of hydroxyl group and the ability to form intramolecular hydrogen bonding in its molecular structure (Praveena et al., 2014; Middleton et al., 2000).

However, as the concentration of orientin increased above $15 \mu \mathrm{M}$, there was a marked increase in the percentage of cytotoxicity of BV2 microglial cells. For instance, approximately $37 \%$ of an increase was recorded in treatment using $100 \mu \mathrm{M}$ relative to $15 \mu \mathrm{M}$. The cytotoxic effect of orientin above MNTD might be related to the generation of intracellular ROS, which was demonstrated by some other flavonoids (Matsuo et al., 2005). The findings by Matsuo and her colleagues proved that at higher concentrations, flavonoids would have an increased ability to be incorporated into the cells thus, increased the intracellular ROS generating ability as well as the levels of few oxidative metabolites, which subsequently contributed to cell death (Matsuo et al., 2005).

\section{Determination of optimal LPS concentration.}

To determine the concentration of LPS that could induce maximum inflammation on BV2 microglia cells, two parameters were analysed: the release of NO by the cells and cell cytotoxicity. The optimal concentration of LPS that was selected in this study is the concentration that would cause the cells to release a significant amount of NO but insignificantly cytotoxic to the cells.

Under physiological conditions, NO acted as neuromodulator and neurotransmitter in the brain that helped to maintain the function of neuronal and vascular cells (Lowenstein et al., 1994). There are two types of NO synthase (NOS) enzymes involved in the production of NO: neuronal NOS (nNOS) and endothelial NOS (eNOS) (Bredt \& Snyder, 1990). They are calcium $\left(\mathrm{Ca}^{2+}\right)$-dependent enzymes, which are constitutive forms of NOS (Bredt \& Snyder, 1990). Nevertheless, NO has been selected as a parameter of neuroinflammation in many studies, including the present study due to its well-known role under pathological conditions in CNS (Ghasemi \& Fatemi, 2014). The inflammatory stimuli will induce the expression of iNOS in activated microglial cells and lead to NO production (Dello Russo et al., 2004). Overproduction of $\mathrm{NO}$ has been correlated with many neurodegenerative disorders, such as Alzheimer's disease, Parkinson's disease, multiple sclerosis, and amyotropic lateral sclerosis (Yuste et al., 2015).

Findings from this study showed a significant dose-dependent increase in the release of $\mathrm{NO}$ by BV2 microglia cells (Figure2A). As LPS concentration increased to $0.1,1.0$, and 10.0 
$\mu \mathrm{g} / \mathrm{mL}$, the produced $\mathrm{NO}$ were $2.33,3.98$, and $4.10 \mu \mathrm{M}$, respectively, which were higher than NO produced by the cells in the control group. It was most probably due to the upregulation of iNOS in LPS-induced BV2 microglia cells through various pathways, such as NF- $\mathrm{\kappa B}$, c-Jun NH2-terminal kinase (JNK) MAPK, and p38MAPK (Lee et al., 2012; Svensson et al., 2010; Oh et al., 2010). On the other hand, the results also demonstrated that even in the absence of LPS, NO was still being produced. Under normal conditions, the neuron cells will produce a low concentration of $\mathrm{NO}$, in which it will act as neurotransmitter that involves in many biological effects (Snyder, 1995).

As for the effect of LPS on the viability of BV2 microglial cells, the present study demonstrated an insignificant decrease in the percentage of cell viability in a dose dependent manner (Figure 2B). Figure 2B illustrates that as the concentration of LPS increased from 0 to 0.1 , 1.0 , and $10.0 \mu \mathrm{g} / \mathrm{mL}$, the percentage of cell viability decreased to $10.76,11.52$, and $14.18 \%$, respectively. In terms of its morphology, the observation was in accordance with the findings by Dai et al., whereby the untreated cells showed small soma with distal arborization, characteristic of "ramified" microglia (Figure 2C) while the 10.0 $\mu \mathrm{g} / \mathrm{mLLPS}$-treated BV2 cells showed fewer branches that were shorter (Figure 2D) and/or appeared to be resorbed into the cell body (Dai et al., 2015). It is postulated that the cytotoxic effect of LPS on BV2 microglial cells could be via coexpression of nicotinamide adenine dinucleotide phosphate (NADPH) oxidase (Mander \& Brown, 2005). The NADPH oxidase is an enzyme responsible for the production of intracellular ROS, such as superoxide $\left(\mathrm{O}_{2}^{-}\right)$, which is important to kill the pathogens that infected the body (Qin \& Crews, 2012; Gandhi \& Abramov, 2012). However, a prolonged inflammation process will lead to the excessive production of several other potent free radicals, such as peroxynitrite, which will kill all cells nearby the inflammation site through protein oxidation, lipid peroxidation and DNA damage, eventually leading to neuronal death (Mander \& Brown, 2005; Wilkinson \& Landreth, 2006; Possel et al., 2000).
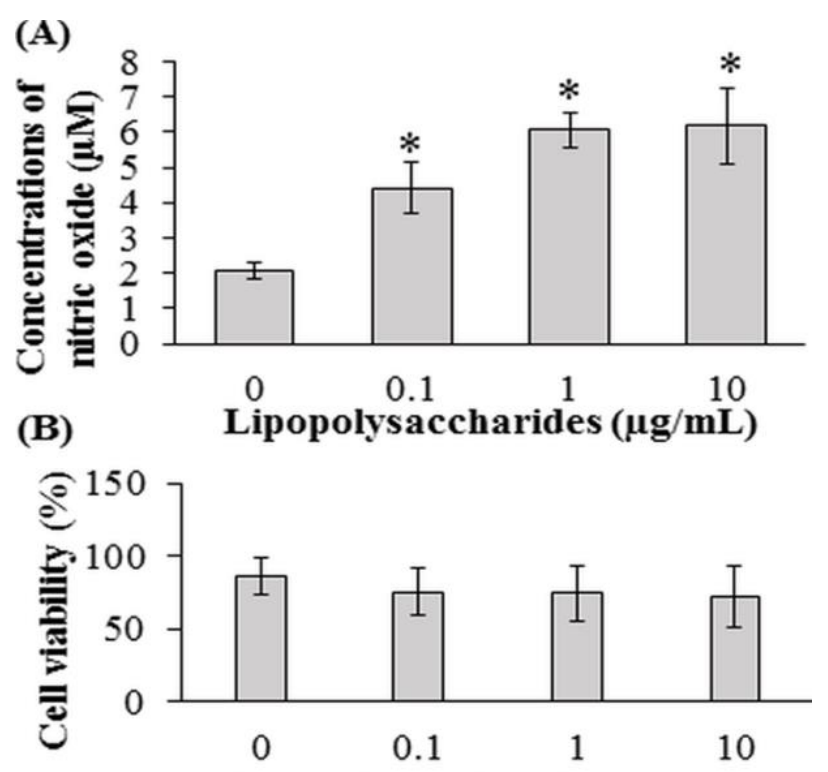

Lipopolysaccharides $(\mu \mathrm{g} / \mathrm{mL})$

(C)

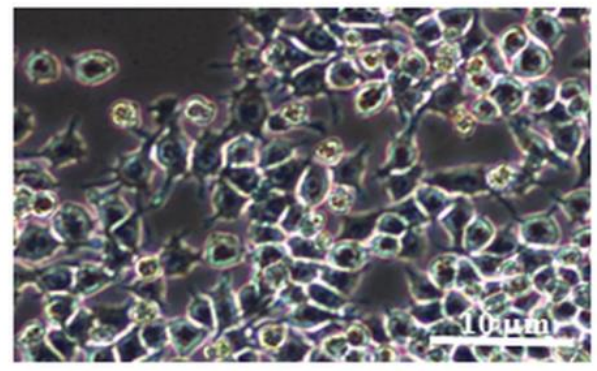

(D)

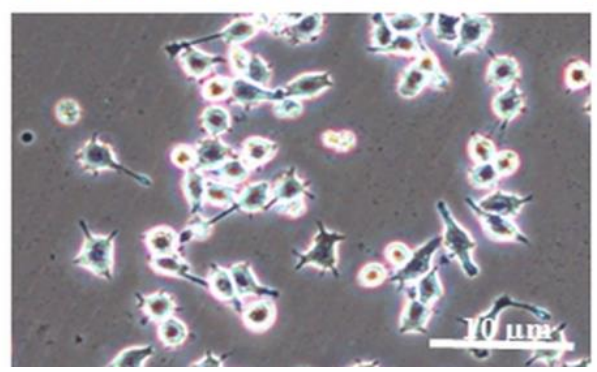

Figure 2. Effect of various concentrations of LPS on (A) concentration of $\mathrm{NO}(\mathrm{B})$ cell viability (C) morphology of the untreated BV2 microglial cells under 100x magnification (D) morphology of the cells treated with $10.0 \mu \mathrm{g} / \mathrm{mL}$ LPS under $100 \mathrm{x}$ magnification. The concentration of NO was measured by Griess reagent while the cell viability was measured by MTT assay. ' $*$ ' denotes significantly different from control at $p<0.05$ using one way analysis of variance followed by Tukey's multiple comparison test. LPS, lipopolysaccharide; NO, nitric oxide.

As illustrated in Figure 2A, a significant inflammation as exhibited through $112 \%$ of increase in NO level was observed in cells treated 
with $0.1 \mu \mathrm{g} / \mathrm{mL}$ LPS. This same concentration of LPS did not cause any significant cytotoxicity towards BV2 cells (Figure 2B). Thus, $0.1 \mu \mathrm{g} / \mathrm{mL}$ of LPS is considered as the optimal concentration to be used in the following studies.

Determination of ROS level. ROS is a redox signal that can be produced by various enzymatic reactions and chemical processes (Hsieh et al., 2013). Low concentration of ROS are known to be essential in physiological functions and acted as second messengers (Hsieh et al., 2013). However, excessive production of ROS have implicated the pathogenesis of human diseases, such as ND. This is probably due to the imbalance redox states resulting in oxidative stress. Studies had shown that cumulative oxidative stress can lead to cellular damage, impairment of DNA repair system and mitochondrial dysfunction, which eventually accelerated the aging process and the development of ND (Gandhi \& Abramov, 2012; Federico et al., 2012; Patten et al., 2010). Hence, it is important to suppress the release of ROS levels in order to prevent ND.

The release of LPS-induced ROS levels in different treatments were determined in this study. As exhibited in Figure 3, the LPS-stimulated microglia cells showed significant upregulation of ROS levels compared to the untreated cells. This suggested that LPS plays an important role in the upregulation of ROS level. Studies suggested that this could be due to the upregulation of NADPH oxidase (Patten et al., 2010). Han et al. (2012) showed the upregulation of the transcriptional levels of two NADPH oxidase components, $\mathrm{p} 47^{\text {phox }}$ and $\mathrm{gp} 91^{\text {phox }}$ by LPS, suggesting the upregulation of NADPH oxidase upon LPS treatment, which resulted in an increase in the production of ROS levels (Qin et al., 2004).

On the other hand, present studies also suggested that orientin at both MNTD and $1 / 2$ MNTD showed significant downregulation of LPS-induced ROS levels by $35.75 \%$ and $47.04 \%$ respectively (Figure 3). Of which, orientin at $1 / 2$ MNTD was found to be more effective than its MNTD, possibly due to the fact that an increase in the concentration of orientin could also lead to an increase in the intracellular stress of the cells, thus increases the ROS levels. The probable mechanism of orientin in reducing the LPSinduced ROS levels might be through the suppression of the two NADPH oxidase components, $\mathrm{p} 47^{\text {phox }}$ and $\mathrm{gp} 91^{\text {phox }}$. The study by Ganet al showed that glaucocalyxin B (GLB) markedly inhibited the expression of $\mathrm{p} 47^{\text {phox }}$ and gp91 ${ }^{\text {phox }}$, which resulted in the inhibition of NADPH oxidase with subsequent downregulation of ROS production (Gan et al., 2015). In addition, quercetin and isorhamnetin were shown to inhibit the expression of $\mathrm{p} 47^{\text {phox }}$ subunit, with subsequent decreased in $\mathrm{O}_{2}{ }^{-}$ production, suggesting the correlation between NADPH oxidase and the production of ROS levels (Sanchez et al., 2007). Furthermore, there were increasing evidences suggesting the upregulation of HO-1 in response to the oxidative stress as a natural anti-oxidant (Loboda et al., 2016). For instance, orientin was shown to alleviate oxidative stress through the induction of Nrf2 translocation to nucleus, which then upregulated the expression of HO-1 and activated the redox signaling pathway (Shih et al., 2015). Consequently, downregulating the ROS level in A 1-42-induced mouse model of AD (Shih et al., 2015). In short, the probable mechanisms of orientin in downregulating the ROS level might be through the inhibition of NADPH oxidase, and the upregulation of HO-1 warrants further study.

Determination of $\mathbf{N F - \kappa B}$ expression. NF- $\mathrm{B}$ is a transcription factor that are responsible for the transcription of genes, such as chemokines, proinflammatory cytokines, pro-inflammatory enzymes, and other factors in order to regulate the inflammatory responses upon stimulation (Shih et al., 2015). NF-KB resides in the cytoplasm as a heterodimer formed by p50 and p65, physically linked to an inhibitory molecule, IкB- $\alpha$. Upon stimulation, $\mathrm{NF}-\mathrm{\kappa} \mathrm{B}$ signaling pathway will be activated firstly through the phosphorylation of IкB- $\alpha$ subunit, with subsequent proteolytic degradation after detachment from the main NFкB unit (Shih et al., 2015). Then, the NF-кB p65 unit will translocate into nucleus and bind to promoter of pro-inflammatory cytokines and enzymes, which eventually resulted in the transcription into respective cytokines or proteins, such as TNF- $\alpha$, IL-1B, IL-6 iNOS and COX-2, and hence their upregulation expressions (Shih et al., 2015). 


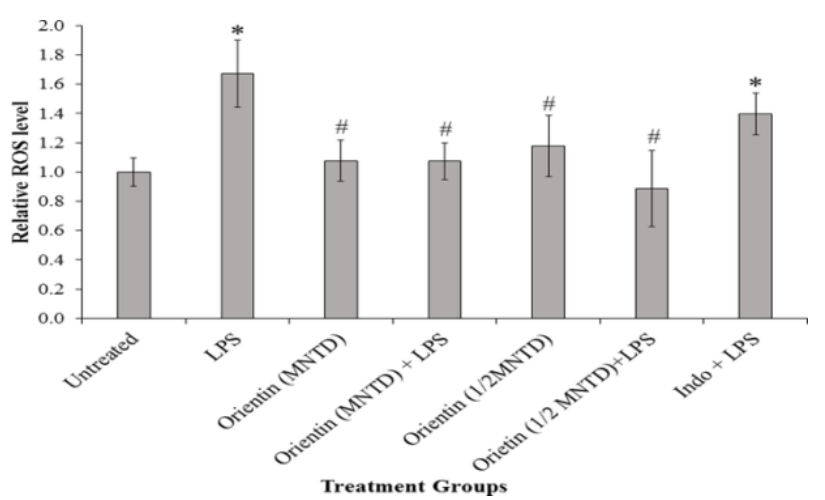

Figure 3. Relative reactive oxygen species (ROS) level in LPS-stimulated BV2 cells upon treatment with $1 / 2$ MNTD and MNTD oforientin. ROS level after 24 hourswas measured by 2',7'-dichlorofluorescindiacetate (DCFH-DA) method. Bars indicate the means \pm standard deviation. ' $*$ ' indicates that the treatment was significantly different from the untreated cells using using one way analysis of variance followed by Tukey's multiple comparison testat $p<0.05$. '\#' denotes the treatment was significantly different from the LPS-stimulated cells using using one way analysis of variance followed by Tukey's multiple comparison test at $p<0.05$. LPS, lipopolysaccharide; MNTD, Maximum Nontoxic Dose of orientin $(15 \mu \mathrm{M}) ; 1 / 2$ MNTD, half value of Maximum Non-toxic Dose of orientin $(7.5 \mu \mathrm{M})$; Indo, Indomethacin.

In this study, the expression of LPS-induced NF$\mathrm{kB}$ were downregulated significantly after the pretreatment of orientin at both MNTD and $1 / 2$ MNTD by $85.29 \%$ and $85.87 \%$ respectively (Figure 4A). Similar finding was shown in Glaucocalyxin B (GLB) whereby the expression of $\mathrm{NF}_{-\kappa \mathrm{K}}$ was suppressed. The suppression mechanisms shown by GLB was through the inhibition of IKK phosphorylation, IКB- $\alpha$ phosphorylation and degradation, as well as the inhibition of NF-KB promoter (Gan et al., 2015). Besides, both anthocyanins and dihydromyricetin isolated from Ampelopsis grossedentata also shown the inhibition of phosphorylation and degradation of $\mathrm{I} \kappa \mathrm{B}-\alpha$ in suppressing the inflammatory responses (Jeong et al., 2013; Hou et al., 2015). Olajide et al. (2013) also demonstrated that the suppression of NF-кB expression by cryptolepine was through the inhibition of nuclear translocation of $\mathrm{NF}-\mathrm{KB}$. Hence, the probable mechanism of orientin in suppressing the expression of NF-кB might be through the similar pathways. Nevertheless, the activation of these transcription factors was not investigated in the present study and thus, should be validated in the future.

Determination of STAT1 expression. Besides NF-кB, STAT1 is also a transcription factor. Stimulation by stimulus such as LPS will eventually lead to the activation of STAT1, which then mediated the transcription of STAT1responsive genes (Rezao-Zadeh et al., 2008). Binding of LPS-induced interferons (IFNs) had shown to increase STAT DNA binding activity and eventually resulted in the phosphorylation of STAT1 (Rezao-Zadeh et al., 2008). This was then followed by dimerization and nuclear translocation of STAT1, resulting in the transcription of STAT1-responsive genes, such as iNOS, IL-1 $\beta$, and IL-6 (Rezao-Zadeh et al., 2008).

In this study, STAT1 expression was shown to be upregulated by 4 folds upon LPS stimulation (Figure 4B). Incubation with LPS for 24 hours had resulted in the over-stimulation of BV2 microglia cells and this eventually contributing to the active STAT1, which was responsible for producing pro-inflammatory cytokines or proteins. However, pre-treatment of the BV2 microglia cells with orientin had significantly downregulated the STAT1 expression. The results showed the reduction of STAT1 expression by $71.15 \%$ at MNTD of orientin and $60.85 \%$ at $1 / 2$ MNTD of orientin. Up to now, not many studies have been conducted on STAT1. However, based on a study carried out on luteolin, Kao et al. demonstrated the inactivation of STAT1 through the attenuation of upstream stimulatory kinases such as IFN- $\gamma$, which then inhibited the downstream pathways and eventually downregulated the production of proinflammatory cytokines (Kao et al., 2011). Hence, it was postulated that orientin probably also acted through the same way. Nevertheless, the activation of these transcription factors warrants further study.

Determination of iNOS expression. iNOS, an enzyme encoded by Nitric oxide synthase 2 (NOS2) gene, generates nitric oxide (NO) from amino acid L-arginine (Lirk et al., 2002). The production of NO plays an important role in the 
pathogenesis of neuroinflammation (Sharma et al., 2007). In normal physiological conditions, NO production gives an anti-inflammatory effects (Sharma et al., 2007). However, excessive NO production will be considered as proinflammatory mediators that induces the neuroinflammation and eventually leads to neuronal cell death (Yuste et al., 2015; Lirk et al., 2002; Sharma et al., 2007). Studies suggested the activation of glia cells expressing the enzyme iNOS produced NO, which then triggered calcium mobilization and activated the release of vesicular glutamate from astroglia cells (Yuste et al., 2015). This eventually resulted in progressive neuronal cell death, contributing to ND (Yuste et al., 2015). Besides, Kroncke et al. showed that high levels of iNOS protein were found in the brains of post-mortem Alzheimer's and Parkinson's diseases patients. Similarly, elevated iNOS level was found in the degenerating infarct region in transgenic mouse model of Hutington's disease (Chen et al., 2000). In addition, strong iNOS immune-reactivity was also detected in activated astrocytes in ALS (Barbeito et al., 2004). All these studies suggested the lethal effects of high iNOS expression. Hence, it is necessary to suppress the expression of iNOS.

In this study, the LPS-simulated BV2 microglia cells showed approximately 4 folds increase in the iNOS expression (Figure 4C). This was known to be highly related to the activation of NF-кB and STAT1 pathway as discussed above, which resulted in the transcription and upregulation of iNOS. However, pre-treatment of the cells with orientin at MNTD showed significant downregulation of the LPS-induced iNOS expression by $50.09 \%$, whereas it showed $95.92 \%$ at $1 / 2$ MNTD of orientin (Figure 4C). Effectiveness of orientin at $1 / 2$ MNTD over its MNTD was in accordance with the present findings on ROS level as iNOS expression could be ROS-dependent. Similar findings were obtained in torilin and geniposide, whereby iNOS expression was suppressed in LPS-induced N9 and BV2 microglia cells, respectively (Choi et al., 2009; Zhang et al., 2012). This downregulation of iNOS expression in both torilin and geniposide was known to be due to the inhibition of NF-кB pathway (Choi et al., 2009; Zhang et al., 2012). Study by Zhang et al. showed that geniposide inhibited the IкB- $\alpha$ subunit degradation and subsequent translocation of $\mathrm{NF}-\mathrm{\kappa} \mathrm{B}$ into nucleus (Zhang et al., 2012). This eventually inhibited the production of iNOS and led to the downregulation of iNOS expression. Therefore, the inhibition of NF-kB signaling pathway might be a possible mechanism of orientin in downregulating iNOS expression.

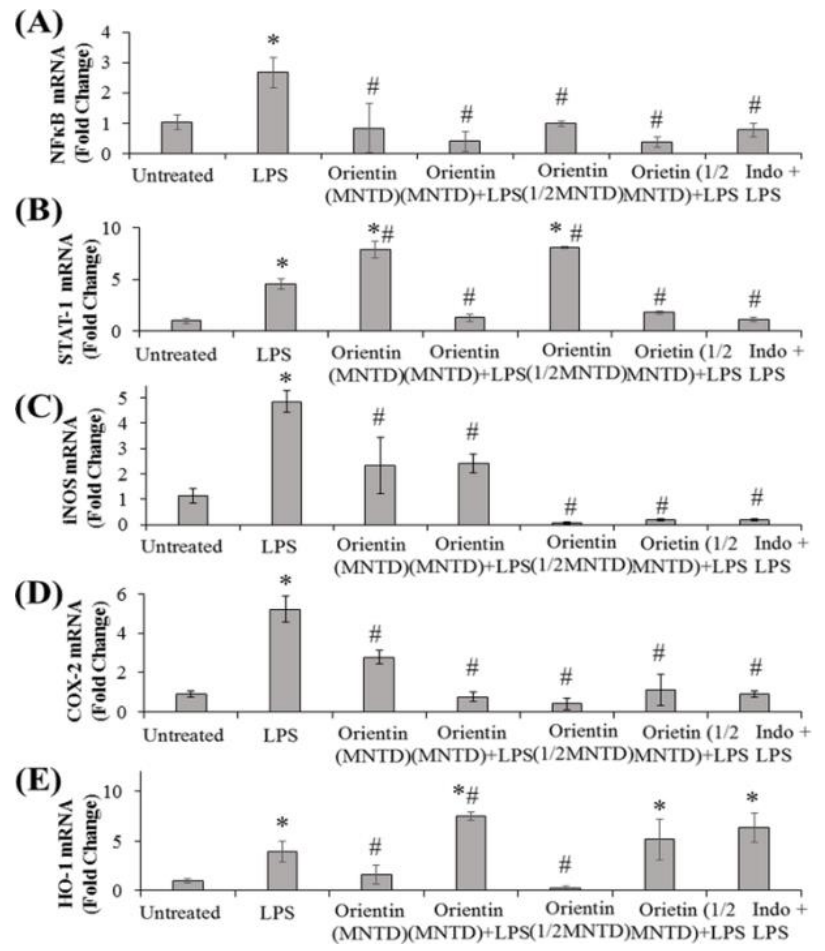

Figure 4. Relative mRNA expression (Fold Change) of (A) NF-кB (B) STAT1 (C) iNOS (D) COX-2 (E) HO-1 in LPS-stimulated BV2 cells upon treatment with $1 / 2$ MNTD and MNTD of orientin. Cells were treated for 24 hoursand gene expression was calculated using Double Delta CT analysis. Bars indicate the means \pm standard deviation. ' $*$ ' indicates that the treatment was significantly different from the untreated cells using one way analysis of variance followed by Tukey's multiple comparison testat $p<0.05$. '\#' denotes the treatment was significantly different from the LPS-stimulated cells using using one way analysis of variance followed by Tukey's multiple comparison testat $p<0.05$. LPS, lipopolysaccharide; MNTD, Maximum Non-toxic Dose of orientin $(15 \mu \mathrm{M})$; $1 / 2$ MNTD, half value of Maximum Non-toxic Dose of orientin $(7.5 \mu \mathrm{M})$; Indo, Indomethacin; iNOS, induciblenitric oxide synthase; COX-2, cyclooxygenase 2; STAT1, signal transducerand activator of transcription 1 ; NF- $\mathrm{KB}$, nuclear factor-кB; HO-1, hemeoxygenase 1 . 
Determination of $\mathrm{COX}-2$ expression. $\mathrm{COX}-2$ is an enzyme encoded by prostaglandinendoperoxide synthase 2 (PTGS 2) gene. It involved in the synthesis of prostaglandin $\mathrm{H} 2$ from arachidonic acid where overproduction will result in neurotoxicity (Ricciotti \& Fitzgerald, 2011; Minghetti, 2004). Studies suggested that COX-2 was expressed in the central nervous system (CNS) under normal condition and it contributed to synaptic activity, long term memory and also helped in functional hyperemia (Minghetti, 2004). When there were proinflammatory activities, expression level of COX2 was known to be elevated in the brain and played a crucial role in inflammatory reactions involving in the pathogenesis of ND (Ricciotti \& Fitzgerald, 2011). For instance, there were elevated levels of COX-2 mRNA and protein found in post-mortem spinal cords of ALS patients (Yasojima et al., 2001). Besides that, studies also showed increased expression level of COX-2 in microglia cells from idiopathic PD patients (Knott et al., 2000). These suggested COX-2 as one of the potential targets used in treating ND.

As shown in Figure 4D, LPS significantly upregulated the COX-2 expression by 4 -fold as compared to the untreated cells. This drastic upregulation of COX-2 expression was also known to be due to the activation of NF-kB pathway (Rezai-Zadeh et al., 2008). Upon treatment, both MNTD and $1 / 2$ MNTD of orientin significantly downregulated COX-2 expression in LPS-induced BV2 cells by $85.3 \%$ and $78.3 \%$, respectively. These findings were in accordance with various studies that suggested the attenuation of LPS-induced COX-2 expression upon treatment with natural compounds. For instance, astaxanthin showed the inhibition of COX-2 expression in LPS-stimulated BV2 microglia cells (Choi et al., 2008). Besides, Kang et al. (2004) suggested the suppression of LPSinduced COX-2 expression in BV2 microglia cells by curcumin through the inhibition of NF-KB and AP-1 DNA bindings. Another study by Yoon et al. (2016) showed that Cudratricusxanthone A suppressed the expression of both iNOS and COX-2 in LPS-stimulated BV2 microglia cells and this inhibitory effects were known to be due to the inhibition of NF-кB and p38 MAPK pathways. Therefore, the probable mechanism of suppression of COX-2 might be via the inhibition of NF-кB pathway, which was also the probable mechanism for iNOS as discussed in the previous section.

However, it was noted that the COX-2 expression (Figure 4D) in LPS-stimulated BV2 microglia cells at both MNTD and $1 / 2$ MNTD orientin were independent of iNOS (Figure 4C). There are studies suggesting that the decrease in iNOS would increase the COX-2 activity through the inhibition of NO production (Patel et al., 1999; Clancy et al., 2000; Habib et al., 1997). For instance, study by Patel et al. suggested that inhibition of nitrite accumulation with high concentration of iNOS inhibitor (L-NMMA) in activated murine macrophage (RAW 264.7) showed the upregulation of PGE2 production and the accumulation of COX-2 protein (Patel et al., 1999). Hence, this could be the possible reason that iNOS and COX-2 acted independently in this study.

Determination of HO-1 expression. HO-1 as an anti-inflammatory enzyme, is enzyme encoded by hemeoxygenase (decycling) 1 (HMOX1) gene located on chromosome 22q12 (Alzaraz et al., 2003; Schipper et al., 2009). HO-1 are responsible for degrading heme to generate carbon monoxide, biliverdin and free iron. It is a normal mechanism in response to oxidative stress or nitrosative stress caused by the high ROS/RNS levels (Kwon et al., 2017). It will also be induced by cytokines or mediators formed during inflammatory processes in order to exert a negative feedback mechanism for cell activation and mediators production, which eventually regulates the inflammatory response (Kwon et al., 2017).

In this study, orientin at MNTD showed a significant upregulation of LPS-induced HO-1 by approximately 4-fold as opposed to untreated cells (Figure 4E). Similar findings were also demonstrated with flavonolquercetin whereby it showed significant upregulation of Nuclear factor-like 2 (Nrf2) and HO-1 expression after LPS exposure (Kwon et al., 2017). This suggested the induction of HO-1 by orientin most probably occurred via Nrf2 pathway. Besides, Kwon et al. (2017) also suggested the reduction of proinflammatory cytokines production via Nrf2/HO-1 signaling pathway by trythanthrin. Another study by Zhou et al. (2014) on Orientin- 
2"-O-Galactopyranoside (OGA) in BV2 microglia cells also demonstrated the significant induction in $\mathrm{Nrf2}$ expression, suggesting the induction of HO-1 expression was mediated by Nrf2 activation. Furthermore, xanthohumol was reported to exert anti-inflammatory properties in
BV2 microglia cells through Nrf2-ARE signaling and the upregulation of downstream HO-1 (Lee et al., 2011). Thus, it is also hypothesized that the probable mechanism of orientin was via the Nrf2 pathway.

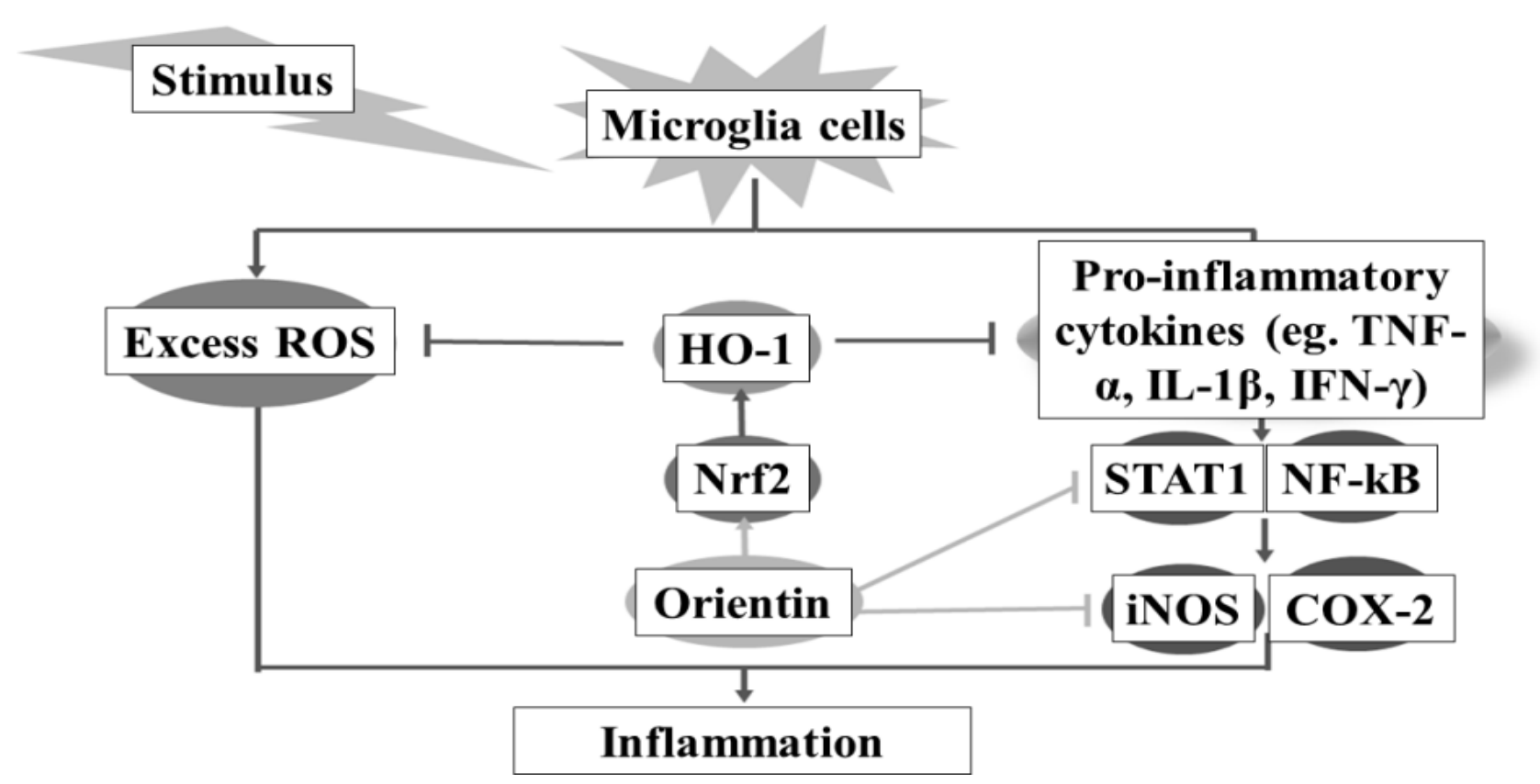

Figure 5. Probable mechanism of orientin. Orientin inhibit the production of pro-inflammatory components such as STAT1, NF-кB, iNOS and COX-2, whereas promote the production of antiinflammatory component, HO-1, which eventually leads to anti-inflammation.

\section{CONCLUSION}

In conclusion, this study showed that orientin at both MNTD and $1 / 2$ MNTD was able to downregulate the ROS level. Orientin was also shown to be able to significantly downregulate the mRNA expression of transcriptional factor, such as NF-кB and STAT 1, as well as the downregulation of pro-inflammatory mediators, such as iNOS and COX-2 significantly. In addition, orientin was also capable of upregulating HO-1. Based on all these findings, the probable mechanism of orientin was summarized and illustrated in Figure 5, which further validates the potential of orientin as an alternative therapeutic agent in treating ND. Nevertheless, additional studies, for instance, detecting the effects of orientin on other key inflammatory cytokines, such as IL-1 $\beta$ and TNF- $\alpha$, in vivo study in evaluating the capacity of orientin to achieve effective concentration in the brain of animal models with neurodegenerative conditions as well as investigating the bioavailability. The neuroprotective effect of orientin in animal models of neuroinflammatory diseases should be further carried out prior to developing orientin as a potential drug in treating ND.

\section{ACKNOWLEDGEMENTS}

The authors would like to thank Dr. Sharmili Vidyadaran for generously providing the BV2 microglial cells. The authors also wish to thank $\mathrm{H}$. Ling of Columbia University (New York, USA) for his editorial input. This study was supported by International Medical University [MBT I2015(01)] and [MBT I-2016 (02)]. 


\section{REFERENCES}

Ackerman, K., Fiddler, J., Soh, T., \& Clarke, S. 2015. BV2 microglial cells used in a model of neuroinflammation. The FASEB Journal 29(1): 608.2.

Ahmed, A. U., Williams, B. R. G., \& Hannigan, G. E. 2015. Transcriptional activation of inflammatory genes: mechanistic insight into selectivity and diversity. Biomolecules 5: 3087-3111.

Ajmone-Cat, M. A., Bernardo, A., Greco, A., \& Minghetti, L. 2010. Non-steroidal anti-inflammatory drugs and brain inflammation: Effects on microglial functions. Pharmacenticals 3: 1949-1964.

Alcaraz, M. J., Fernández, P., \& Guillén, M. I. 2003. Antiinflammatory actions of the heme oxygenase- 1 pathway. Current Pharmaceutical Design 9: 2541-2551.

An, F., Yang, G. D., Tian, J. M., \& Wang, S. H. 2012. Antioxidant effects of the orientin and vitexin in trollius chinensis bunge in d-galactose-aged mice. Neural Regeneration Research 7: 2565-2575.

Bae, J. S. 2015. Inhibitory effect of orientin on secretory Group IIA phospholipase A2. Inflammation 38: 1631-1638.

Barbeito, L. H., Pehar, M., Cassina, P., Vargas, M. R., Peluffo, H., Viera, L., Estevez, A. G., \& Beckman, J. S. 2004. A role for astrocytes in motor neuron loss in amyotrophic lateral sclerosis. Brain Research Reviews 47: 263-274.

Bredt, D. S., \& Snyder, S.H. 1990. Isolation of nitric oxide synthetase, a calmodulin-requiring enzyme. Proceedings of the National Academy of Sciences of the US A 87: 682-685.

Chau, L. Y. 2015. Heme oxygenase-1: emerging target of cancer therapy. Journal of Biomedical Science 22: 22.

Chen, M., Ona, V. O, Li M, Ferrante, R. J., Fink, K. B., Zhu, S., Bian, J., Guo, L., Farrell, L. A., Hersch, S. M., Hobbs, W., Vonsattel, J. P., Cha, J. H., \& Friedlander, R. M. 2000. Minocycline inhibits caspase- 1 and caspase- 3 expression and delays mortality in a transgenic mouse model of Huntington disease. Nature Medicine 6: 797-801.

Chen, W. W., Zhang, X., \& Huang, W. J. 2016. Role of neuroinflammation in neurodegenerative diseases. Molecular Mediccine Reports 13: 3391-3396.

Choi, S. K., Park, Y. S., Choi, D. K., \& Chang, H. I. 2008. Effects of astaxanthin on the production of $\mathrm{NO}$ and the expression of COX-2 and iNOS in LPS-stimulated BV2 microglial cells. Journal Microbiology and Biotechnology 18(12): 1990-1996.

Choi, Y., Lee, M. K., Lim, S. Y., Sung, S. H., \& Kim, Y. C. 2009. Inhibition of inducible NO synthase, cyclooxygenase- 2 and interleukin- $1 \beta$ by torilin is mediated by mitogen-activated protein kinases in microglial BV2 cells. British Journal of Pharmacology 156: 933-940.

Clancy, R., Varenika, B., Huang, W., Ballou, L., Attur, M., Amin, A.R., \& Abramson, S. B. 2000. Nitric oxide synthase/COX cross-talk: nitric oxide activates COX-1 but inhibits COX2-derived prostaglandin production. Journal of Immunology 165: 1582-1587.

Da Silva, R. Z., Yunes, R. A., De Souza, M. M., Monache, F. D., \& Cechinel-Filho, V. 2010. Antinociceptive properties of conocarpan and orientin obtained from Piper solmsianum C. DC. var. solmsianum (Piperaceae). Journal of Natural Medicines 64: 402-408.

Dai, X. J., Li, N., Yu, L., Chen, Z. Y., Hua, R., Qin, X., Zhang, Y. M. 2015. Activation of BV2 microglia by lipopolysaccharide triggers an inflammatory reaction in PC12 cell apoptosis through a toll-like receptor 4-dependent pathway. Cell Stress and Chaperones 20:321-331.

Dello Russo, C., Boullerne, A. I., Gavrilyuk, V., \& Feinstein, D. L. 2004. Inhibition of microglial inflammatory responses by norepinephrine: effects on nitric oxide and interleukin-1 $\beta$ production. Journal of Neuroinflammation 1:9.

Dröge, W. 2002. Free radicals in the physiological control of cell function. Physiological Reviews 82: 47-95.

Federico, A., Cardaioli, E., Da Pozzo, P., Formichi, P., Gallus, G. N., \& Radi, E. 2012. Mitochondria, oxidative stress and neurodegeneration. Journal of the Neurological Sciences 322: 254-262.

Frank-Cannon, T. C., Alto, L. T., McAlpine, F. E., \& Tansey, M. G. 2009. Does neuroinflammation fan the flame in neurodegenerative diseases? Molecular Neurodegeneration 4: 47.

Fu, X. C., Wang, M. W., Li, S. P., Zhang, Y., \& Wang, H. L. 2005. Vasodilatation produced by orientin and its mechanism study. Biological and Pharmaceutical Bulletin 28: 37-41.

Gan, P., Zhang, L., Chen, Y., Zhang, F., Zhou, X., Gao, B., Zhen, X., Zhang, J., Zheng, L. T. 2015. Anti-inflammatory effects of glaucocalyxin B in microglia cells. Journal of Pharmacological Sciences 128: 35-46.

Gandhi, S. \& Abramov, A. Y. 2012. Mechanism of oxidative stress in neurodegeneration. Oxidative Medicine and Cellular Longevity 2012: Article ID 428010.

Ghasemi, M. \& Fatemi, A. 2014. Pathologic role of glial nitric oxide in adult and pediatric neuroinflammatory diseases. Neuroscience \& Biobehavioral Reviews 45: 168-182.

Habib, A., Bernard, C., Lebret, M., Creminon, C., Esposito, B., Tedgui, A., \& Maclouf, J. 1997. Regulation of the expression of cyclooxygenase- 2 by nitric oxide in rat peritoneal macrophages. Journal of Immunology 158: 3845 3851.

Han, J. E. \& Choi, J. W. 2012. Control of JNK for an activation of NADPH oxidase in LPS-stimulated BV2 microglia. Archives of Pharmaceutical Research 35: 709-715.

Henn, A., Lund, S., Hedtjärn, M., Schrattenholz, A., Pörzgen, P., \& Leist, M. 2009. The suitability of BV2 cells as alternative model system for primary microglia cultures or for animal experiments examining brain inflammation. ALTEX 26(2): 83-94.

Himaya, S. W. A., Ryu, B., Qian, Z. J., \& Kim, S. K. 2012. Paeonol from Hippocampus kuda Bleeler suppressed the neuroinflammatory responses in vitro via NF-kB and MAPK signaling pathways. Toxicology In Vitro 26: 878-887.

Hou, X. L., Tong, Q., Wang, W. Q., Shi, C. Y., Xiong, W., Chen, J., Liu, X., \& Fang, J. G. 2015. Suppression of inflammatory responses by dihydromyricetin, a flavonoid from Ampelopsis grossedentata, via inhibiting the activation of NF-kB and MAPK signaling pathways. Journal of Natural Products 78: 1689-1696.

Hsieh, H. L. \& Yang, C. M. 2013. Role of redox signaling in neuroinflammation and neurodegenerative diseases. Biomed Research International 2013: 2013.

Jaeger, L. B., Dohgu, S., Sultana, R., Lynch, J. L., Owen, J. B., Erickson, M. A., Shah, G. N., Price, T. O., FleegalDemotta, M. A., Butterfield, D. A., Banks, \& W. A. 2009. Lipopolysaccharide alters the blood-brain barrier transport of amyloid $\beta$ protein: A mechanism for inflammation in the progression of Alzheimer's disease. Brain Behavior and Immunology 23: 507-517.

Jeong, J. W., Lee ,W. S., Shin, S. C., Kim, G. Y., Choi, B. T. \& Choi, Y. H. 2013. Anthocyanins downregulate lipopolysaccharide-induced inflammatory responses in BV2 microglial cells by suppressing the $\mathrm{NF}-x \mathrm{~B}$ and Akt/MAPKs signaling pathways. International Journal of Molecular Sciences 14: 1502-1515.

Kanatani, K., Ebata, M., Murakami, M., \& Okabe, S. 2004. Effects of indomethacin and rofecoxib on gastric mucosal damage in normal and Helicobacter pylori-infected Mongolian gerbils. Journal of Physiology and Pharmacology 55: 207-222.

Kang, G., Kong, P. J., Yuh, Y. J., Lim, S. Y., Yim, S. V., Chun, W. 
and Kim, S. S. 2004. Curcumin suppresses lipopolysaccharide-induced cyclooxygenase- 2 expression by inhibiting activator protein 1 and nuclear factor kappab bindings in BV2 microglial cells. Journal of Pharmacological Sciences 94: 325-328.

Kao, T. K., Ou, Y. C., Lin, S. Y., Pan, H. C., Song, P. J., Raing, S. L., Liao, S. L., Lu, H. C., \& Chen, C. J. 2011. Luteolin inhibits cytokine expression in endotoxin/cytokinestimulated microglia. Journal of Nutritional Biochemistry 22: 612-624.

Katzman, R. 2008. The prevalence and malignancy of Alzheimer disease: a major killer. Alzheimer's \& Dement 4:378-380.

Kenneth, J. L. \& Thomas, D. S. 2002. Analysis of relative gene expression data using real-time quantitative PCR and the 2 $\triangle \Delta$ CT method. Methods 25: 402-408.

Khan, R. A. 2012. Evaluation of flavonoids and diverse antioxidant activities of Sonchus arvensis. Chemistry Central Journal 6: 126.

Kim, D. C., Yoon, C. S., Quang, T. H., Ko, W., Kim, J. S., Oh, H., \& Kim, Y. C. 2016. Prenylated flavonoids from Cudrania tricuspidata suppress lipopolysaccharide-induced neuroinflammatory activities in BV2 microglial cells. International Journal of Molecular Sciences 17: 2016.

Kim, J., Lee, I., Seo, J., Jung, M., Kim, Y., Yim, N., \& Bae, K. 2010. Vitexin, orientin and other flavonoids from Spirodela polyrbiza inhibit adipogenesis in 3T3-L1 cells. Phytotherapy Research 24: 1543-1548.

Knott, C., Stern, G., \& Wilkin, G. P. 2000. Inflammatory regulators in Parkinson's Disease: iNOS, Lipocortin-1, and Cyclooxygenases-1 and -2. Molecular and Cellular Neuroscience 16: 724-739.

Kulkarni, A. P., Kella Way, L. A., \& Kotwal, G. J. 2005. Herbal complement inhibitors in the treatment of neuroinflammation: Future strategy for neuroprotection. In: Annals of the New York. Academy of Sciences. vol. 1056, pp. 413-429.

Kwon, Y. W., Cheon, S. Y., Park, S. Y., Song, J., \& Lee, J. H. 2017. Tryptanthrin suppresses the activation of the LPS-treated BV2 microglial cell line via $\mathrm{Nrf2/HO}-1$ antioxidant signaling. Frontiers of Cellular Neuroscience 11: 18.

Lam, K. Y., Ling, A. P. K., Koh, R. Y., Wong, Y. P., \& Say, Y. H. 2016. A review on medicinal properties of orientin. Advances in Pharmacological Sciences 2016: Article ID 4104595.

Law, B. N. T., Ling, A. P. K., Koh, R. Y., Chye, S. M., \& Wong, Y. P. 2014. Neuroprotective effects of orientin on hydrogen peroxide-induced apoptosis in SH-SY5Y cells. Molecular Medicine Reports 9: 947-954.

Lawrence, T. 2009. The Nuclear Factor NF-KB pathway in inflammation. Perspectives in Biology 1: 1-10.

Lee, I. S., Lim, J., Gal, J., Kang, J. C., Kim, H. J., Kang, B. Y., \& Choi, H. J. 2011. Anti-inflammatory activity of xanthohumol involves heme oxygenase- 1 induction via NRF2-ARE signaling in microglial BV2 cells. Neurochemistry International 58: 153-160.

Lee, K. W., Jung, S. Y., Choi, S. M., \& Yang, E. J. 2012. Effects of ginsenoside Re on LPS-induced inflammatory mediators in BV2 microglial cells. BMC Complementary \& Alternative Medicine 12: 1-8.

Lee, W. \& Bae, J. S. 2015. Antithrombotic and antiplatelet activities of orientin in vitro and in vivo. Journal of Functional Foods 17: 388-398.

Li, D., Wang, Q., Yuan, Z., Zhang, L., Xu, L., Cui, Y., \& Duan, K. 2008. Pharmacokinetics and tissue distribution study of orientin in rat by liquid chromatography. Journal of Pharmaceutical and Biomedical Analysis 47: 429-434.

Li, Q. F., Feng, S. Q., Cen, Y. Z., Yang, Y. T., Wang, L. Y. 2004. Study on the antibacterial and antiviral activity compositions of Trollium chinensis Bunge. Journal of Zhejiang University 31: 412-415.
Lin, C., Lin, H. Y., Chen, J. H., Tseng W. P., Ko, P. Y., Liu, Y. S., Yeh, W. L., \& Lu, D. Y. 2015. Effects of paeonol on antineuroinflammatory responses in microglial cells. International Journal of Molecular Sciences 16: 8844-8860.

Lirk, P., Hoffmann, G. \& Rieder, J. 2002. Inducible nitric oxide synthase--time for reappraisal. Current Drug Targets Inflammation \& Allergy 1: 89-108.

Liu, P. W., Chen, M. F., Tsai, A. P. Y., \& Lee, T. J. F. 2012. STAT1 mediates oroxylin A inhibition of iNOS and proinflammatory cytokines expression in microglial BV2 cells. PLoS One 7:2012.

Loboda, A., Damulewicz, M., Pyza, E., Jozkowicz, A., \& Dulak, J. 2016. Role of Nrf2/HO-1 system in development, oxidative stress response and diseases: an evolutionarily conserved mechanism. Cell and Molecular Life Sciences 73(17): 3221-3247.

Lowenstein, C. J., Dinerman, J. L., \& Snyder, S. H. 1994. Nitric oxide: A physiologic messenger. Annals of Internal Medicine 120: 227-237.

Lull, M. E. \& Block, M. L. 2010. Microglial activation and chronic neurodegeneration. Neurotherapentics 7: 354-365.

Mamdani, M., Juurlink, D. N., Lee, D. S., Rochon, P. A., Kopp, A., Naglie, G., Austin, P. C., Laupacis, A., \& Sukel, T. A. 2004. Cyclo-oxygenase-2 inhibitors versus non-selective non-steroidal anti-inflammatory drugs and congestive heart failure outcomes in elderly patients: A population-based cohort study. Lancet 363: 1751-1756.

Mander, P. \& Brown, G. C. 2005. Activation of microglial NADPH oxidase is synergistic with glial iNOS expression in inducing neuronal death: a dual-key mechanism of inflammatory neurodegeneration. Journal of Neuroinflammation 2: 20.

Massa, P. T., Aleyasin, H., Park, D. S., Mao, X., \& Barger, S. W. 2006. NF-KB in neurons? The uncertainty principle in neurobiology. Journal of Neurochemistry 97: 607-618.

Matsuo, M., Sasaki, N., Saga, K., \& Kaneko, T. 2005. Cytotoxicity of flavonoids toward cultured normal human cells. Biological and Pharmaceutical Bulletin 28: 253-259.

Middleton, E., Kandaswami, C., \& Theoharides, T. C. 2000. The effects of plant flavonoids on mammalian cells: implications for inflammation, heart disease, and cancer. Pharmacological Reviews 52: 673-751.

Minghetti, L. 2004. Cyclooxygenase-2 (COX-2) in inflammatory and fegenerative brain diseases. Journal of Neuropathology \& Experimental Neurology 63:901-910.

Nakajima, K. \& Kohsaka, S. 2001. Microglia: activation and their significance in the central nervous system. Journal of Biochemistry 130: 169-175.

Nayak, V., Nishioka H., \& Uma, P. 2006. Antioxidant and radioprotective effects of Ocimum flavonoids orientin and vicenin in Escherichia coli. Defence Science Journal 56(2): 179187.

Oh, Y. T., Lee, J. Y., Lee, J., Lee, J. H., Kim, J. E., Ha, J., \& Kang, I. 2010. Oleamide suppresses lipopolysaccharide-induced expression of iNOS and COX-2 through inhibition of NF$\mathrm{KB}$ activation in BV2 murine microglial cells. Neuroscience Letter 474: 148-153.

Ohtsuki, S., Yamaguchi, H., Kang, Y. S., Hori, S., \& Terasaki, T. 2010. Reduction of L-type amino acid transporter $1 \mathrm{mRNA}$ expression in brain capillaries in a mouse model of Parkinson's disease. Biological and Pharmaceutical Bulletin 33: $1250-1252$

Olajide, O. A., Bhatia, H. S., De Oliveira, A. C. P., Wright, C. W., \& Fiebich, B. L. 2013. Inhibition of neuroinflammation in LPS-activated microglia by cryptolepine. Evidence-based Complementary and Alternative Medicine 2013: 459723.

Parada, E., Buendia, I., Navarro, E., Avendaño, C., Egea, J., \& López, M. G. 2015. Microglial HO-1 induction by curcumin 
provides antioxidant, anti-neuroinflammatory, and glioprotective effects. Moledular Nutrition and Food Research 59: 1690-1700.

Patel, R., Attur, M. G., Dave, M., Abramson, S. B., \& Amin, A. R. 1999. Regulation of cytosolic COX-2 and prostaglandin E2 production by nitric oxide in activated murine macrophages. Journal of Immunology 162(7): 4191-4197.

Patten, D. A., Germain, M., Kelly, M. A., \& Slack, R. S. 2010. Reactive oxygen species: Stuck in the middle of neurodegeneration. Journal of Alinheimer's Disease 20(s2): S357-S367.

Possel, H., Noack, H., Putzke, J., Wolf, G., \& Sies, H. 2000. Selective upregulation of inducible nitric oxide synthase (iNOS) by lipopolysaccharide (LPS) and cytokines in microglia: In vitro and in vivo studies. Glia 32: 51-59.

Praveena, R., Sadasivam, K., Deepha, V., \& Sivakumar, R. 2014. Antioxidant potential of orientin: A combined experimental and DFT approach. Journal of Molecular Structure 1061: 114123.

Qin, L. \& Crews, F. T. 2012. NADPH oxidase and reactive oxygen species contribute to alcohol-induced microglial activation and neurodegeneration. Journal of Neuroinflammation 9: 491.

Qin, L., Liu, Y., Wang, T., Wei, S. J., Block, M. L., Wilson, B., Liu, B., \& Hong, J. S. 2004. NADPH oxidase mediates lipopolysaccharide-induced neurotoxicity and proinflammatory gene expression in activated microglia. Journal of Biological Chemistry 279: 1415-1421.

Rezai-Zadeh, K., Ehrhart, J., Bai, Y., Sanberg, P. R., Bickford, P., Tan, J., \& Shytle, R. D. 2008. Apigenin and luteolin modulate microglial activation via inhibition of STAT1induced CD40 expression. Journal of Neuroinflammation 5: 41.

Ricciotti, E. \& Fitzgerald, G. A. 2011. Prostaglandins and inflammation. Arteriosclerosis, Thrombosis and Vascular Biology 31: 986-1000.

Rogers, J., Mastroeni, D., Leonard, B., Joyce, J., \& Grover, A. 2007. Neuroinflammation in Alzheimer's disease and Parkinson's disease: are microglia pathogenic in either disorder? International Review of Neurobiology 82: 235-246.

Rojo, L. E., Fernández, J. A., Maccioni, A. A., Jimenez, J. M., \& Maccioni, R. B. 2008. Neuroinflammation: Implications for the pathogenesis and molecular diagnosis of Alzheimer's disease. Archives of Medical Research 39: 1-16.

Sanchez, M., Lodi, F., Vera, R., Villar, I. C., Cogolludo, A., Jimenez, R., Moreno, L., Romero, M., Tamargo, J., Perez-Vizcaino, F., \& Duarte, J. 2007. Quercetin and isorhamnetin prevent endothelial dysfunction, superoxide production, and overexpression of $\mathrm{p} 47 \mathrm{phox}$ induced by angiotensin II in rat aorta. Journal of Nutrition 137: 910-915.

Schipper, H. M., Song, W., Zukor, H., Hascalovici, J. R., \& Zeligman, D. 2009. Heme oxygenase-1 and neurodegeneration: Expanding frontiers of engagement. Journal of Neurochemistry 110: 469-485.

Seo, C. S., Lee, M. Y., Shin, I. S., Lee, J. A., Ha, H., \& Shin, H. K. 2012. Spirodela polyrbiza (L.) Sch. ethanolic extract inhibits LPS-induced inflammation in RAW264.7 cells. Immunopharmacology and Immunotoxicology 34: 794-802.

Sharma, J. N., Al-Omran, A., \& Parvathy, S. S. 2007. Role of nitric oxide in inflammatory diseases. Inflammopharmacology 15: 252-259.

Shih, R. H., Wang, C. Y., \& Yang, C. M. 2015. NF-kappaB signaling pathways in neurological inflammation: A mini review. Frontiers in Molecular Neuroscience 8: 77.

Snyder, S. H. 1995. Nitric oxide: a neural messenger. Annual Review of Cell and Developmental Biology 11: 417-440.

Spencer, J. P. E., Vafeiadou, K., Williams, R. J., \& Vauzour, D. 2012. Neuroinflammation: Modulation by flavonoids and mechanisms of action. Molecular Aspects of Medicine 33(1): 8397.
Streit, W. J., Mrak, R. E., \& Griffin, W. S. T. 2004. Microglia and neuroinflammation: a pathological perspective. Journal of Neuroinflammation 1: 4.

Svensson, C., Fernaeus, S. Z., Part, K., Reis, K.,\& Land, T. 2010. LPS-induced iNOS expression in BV2 cells is suppressed by an oxidative mechanism acting on the JNK pathway-A potential role for neuroprotection. Brain Research 1322: 1-7.

Wilkinson, B. L. \& Landreth, G. E. 2006. The microglial NADPH oxidase complex as a source of oxidative stress in Alzheimer's disease. Journal of Neuroinflammation 3: 30.

Yasojima, K., Tourtellotte, W. W., McGeer, E. G., \& McGeer, P. L. 2001. Marked increase in cyclooxygenase-2 in ALS spinal cord: implications for therapy. Neurology 57: 952-956.

Yoon, C. S., Kim, D. C., Quang, T. H., Seo, J. W., Kang, D. G., Lee, H.S., Oh, H. C., \& Kim, Y. C. 2016. A prenylated xanthone, cudratricusxanthone $\mathrm{A}$, isolated from Cudrania tricuspidata inhibits lipopolysaccharide-induced neuroinflammation through inhibition of NF-KB and p38 MAPK pathways in BV2 microglia. Molecules 21(9): 1240.

Yu, L., Wang, S., Chen, X., Yang, H., Li, X., Xu, Y., \& Zhu, X. 2015. Orientin alleviates cognitive deficits and oxidative stress in A $\beta 1-42$-induced mouse model of Alzheimer's disease. Life Science 121: 104-109.

Yune, T. Y., Lee, S. M., Kim, S. J., Park, H. J., Oh, Y. J., Kim, Y. C., Markelonis, G. J., \& Oh, T. H. 2004. Manganese superoxide dismutase induced by TNF-beta is regulated transcriptionally by NF-kappaB after spinal cord injury in rats. Journal of Neurotrauma 21: 1778-1794.

Yuste, J. E., Tarragon, E., Campuzano, C. M., \& Ros-Bernal, F. 2015. Implications of glial nitric oxide in neurodegenerative diseases. Frontiers in Cellular Neuroscience 9: 322.

Zhang, G., He, J. L., Xie, X. Y., \& Yu, C. 2012. LPS-induced iNOS expression in N9 microglial cells is suppressed by geniposide via ERK, p38 and nuclear factor-KB signaling pathways. International Journal of Molecular Medicine 30: 561568.

Zhou, X., Gan, P., Hao, L., Tao, L., Jia, J., Gao, B., Liu, J. Y., Zheng, L. T., \& Zhen, X. 2014. Antiinflammatory effects of orientin-2"-O-galactopyranoside on lipopolysaccharidestimulated microglia. Biological and Pharmaceutical Bulletin 37: 1282-1294. 